\title{
A FISIOTERAPIA NA PREVENÇÃO E DIMINUIÇÃO DA INCIDÊNCIA DE QUEDAS EM IDOSOS
}

\author{
Claudia Mara Miranda Russi ${ }^{1}$ \\ Gabriela Alejandra Moya Fernandez ${ }^{2}$
}

Resumo: O processo de envelhecimento é um acontecimento fisiológico e traz diversas alterações anatômicas na postura, no sistema articular e osteomuscular, alterações no sistema nervoso e cardiorrespiratório; assim como no sistema imunológico, digestivo, endócrino e metabólico. Estas alterações tornam o idoso mais frágil e propenso a sofrer quedas. As quedas são ocorrências relativamente comuns e constituem causa de morbidade e mortalidade em indivíduos com mais de 65 anos. Portanto, foi realizada uma revisão sistemática, através de uma busca de artigos científicos abordando os temas Idosos/ Fisioterapia/ Quedas, publicadas entre os anos de 2000 a 2016. A partir destes trabalhos espera-se verificar a fisioterapia preventiva aplicada à geriatria enquanto ferramenta para proporcionar uma melhoria na capacidade funcional do idoso.

Palavras-chave: Idosos; Quedas; Fisioterapia; Atividade Física.

\footnotetext{
${ }^{1}$ Faculdade de Fisioterapia / Kroton-Anhanguera Educacional, Brasil. E-mail: russi.claudiam@gmail.com.

${ }^{2}$ Faculdade de Fisioterapia / Kroton-Anhanguera Educacional, Brasil. E-mail: gabi_amf@yahoo.com.br.
} 